\title{
Obituary
}

\section{Jack Peter Green, 1925-2007}

\author{
Neuropsychopharmacology (2007) 32, 2248; \\ doi: 10.1038/sj.npp. 1301517
}

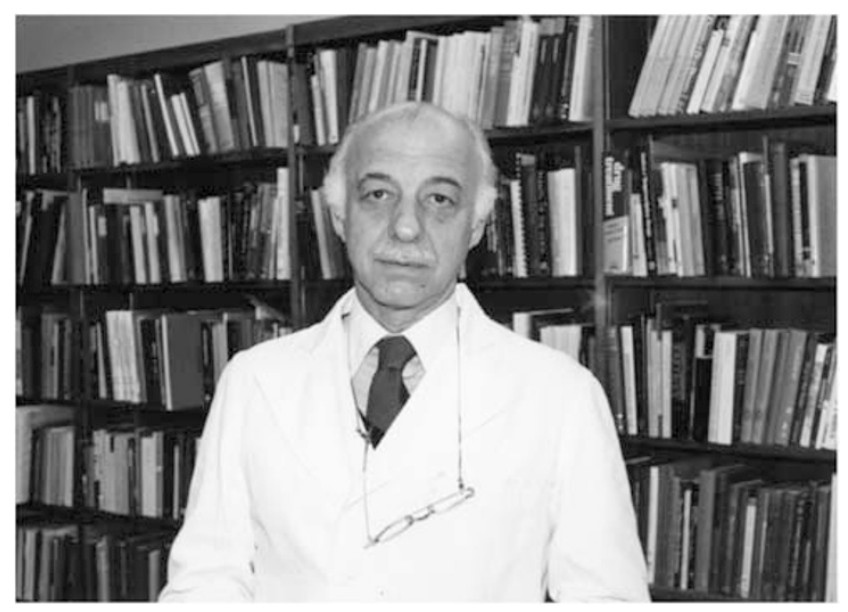

Jack Peter Green, MD, PhD, a long-standing member of the ACNP, died on February 7, 2007. At the time of his passing, Dr Green was Professor Emeritus in the Dorothy $\mathrm{H}$ and Lewis Rosenstiel at Department of Pharmacology and Systems Therapeutics, Mount Sinai School of Medicine. Dr Green was the founding chairperson of the Department of Pharmacology at Mount Sinai School of Medicine and led the department for almost 30 years. Dr Green was trained in pharmacology at Yale University where he obtained his MD and $\mathrm{PhD}$ degrees. Dr Green was on the faculty at Yale and Cornell University Schools of Medicine before joining Mount Sinai School of Medicine to start the Department of Pharmacology. Throughout his tenure, he mentored and supported many young faculty during their formative years, and maintained an active interest and support for both the research and educational missions of the department. $\mathrm{He}$ was a highly regarded pharmacologist, who was best known for his work on histamine. He was an early proponent of histamine and its metabolites as central nervous system neurotransmitters and neuromodulators. He was also among the first to recognize the multiple subtypes of serotonin receptors in the brain. In addition to his activities at Mount Sinai, he devoted considerable energies to national and international professional organizations including the ACNP. He was a Fellow of the ACNP and a member of the Program Committee from 1978 to 1980 and 1982 to 1984 and was on the Ethics Committee in 1984. He served as Chair of the Program Committee in 1982. Dr Green was a strong and influential figure in the development of the field of neuropharmacology. He is survived by his wife Arleyne.

Kenneth L Davis ${ }^{1}$ and Dennis S Charney ${ }^{2}$ ${ }^{1}$ President and CEO, The Mount Sinai Medical Center, One Gustave L Levy Place, New York, NY, USA E-mail: Kenneth.davis@mssm.edu;

${ }^{2}$ Dean, Mount Sinai School of Medicine, One Gustave L Levy Place, New York, NY, USA E-mail: Dennis.charney@mssm.edu 